\title{
PENANAMAN KEMANDIRIAN PADA ANAK USIA DINI DI SEKOLAH
}

\author{
Nurhenti Dorlina Simatupang ${ }^{1}$; Sri Widayati ${ }^{1}$; Kartika Rinakit Adhe ${ }^{1}$; Alfi Nuris Shobah ${ }^{1}$ \\ PG-PAUD, Fakultas Ilmu Pendidikan, Universitas Negeri Surabaya, \\ Jl. Lidah Wetan, Surabaya, 60213 \\ Penulis untuk Korespondensi/ E-mail: nurhentidorlina@unesa.ac.id
}

\begin{abstract}
Abstrak - Penelitian studi kasus ini bertujuan untuk mendeskripsikan penanaman kemandirian pada beragam kegiatan yang membentuk ke arah karakter mandiri anak melalui kegiatan yang ada di sekolah. Teknik pengumpulan data dalam penelitian ini adalah melalui wawancara, observasi dan dokumentasi. Berdasarkan data yang diperoleh, kemandirian anak terwujud melalui kegiatan yang ada di sekolah, antara lain; 1. Pada kegiatan awal masuk kelas dimana anak masuk ke dalam kelas dengan melepas sepatu, peci dan tas kemudian anak meletakkannya ditempat yang telah disediakan, 2. Pada saat kegiatan inti penanaman kemandirian anak terlihat pada kegiatan merapikan mainannya sendiri setelah bermain, 3. Pada kegiatan penutup keluar kelas anak dibiasakan untuk mengenakan tas, peci dan sepatunya sendiri, kemudian anak berbaris dengan rapi tanpa bantuan guru. Semua kegiatan ini diharapkan dapat ditiru oleh seluruh lembaga PAUD di Indonesia dan dapat lebih dikembangkan lagi dengan menambah program-program untuk menstimulasi kemandirian anak. Penanaman karakter mandiri adalah suatu usaha yang dilakukan untuk membentuk sikap dan watak seseorang agar hidupnya tidak terus bergantung pada bantuan orang lain.
\end{abstract}

Kata Kunci: Penanaman, Kemandirian, Anak usia dini.

Abstract - This case study research aims to describe the cultivation of independence in a variety of activities that shape the child's independent character through activities in school. Data collection techniques in this study were through interviews, observation and documentation. Based on the data obtained, children's independence is realized through existing activities at school, including; 1 . In the initial activity of entering the classroom where the child enters the classroom by removing shoes, caps and bags then the child places it in the space provided, 2. During the core activity of planting the independence of the child seen in the activities of tidying his own toys after playing, 3. At closing activities out of the classroom children are accustomed to wearing their own bags, caps and shoes, then children line up neatly without the help of the teacher. All these activities are expected to be emulated by all PAUD institutions in Indonesia and can be further developed by adding programs to stimulate children's independence. The cultivation of independent character is an effort made to shape the attitude and character of a person so that his life does not continue to depend on the help of others.

Keywords: Growing, Independent character values, Early childhood 


\section{PENDAHULUAN}

A nak usia dini adalah sosok individu yang sedang menjalani suatu proses perkembangan dengan pesat dan fundamental bagi kehidupan selanjutnya (Sujiono, 2007: 4). Anak usia dini berada pada rentang usia 0-6 tahun. Pendidikan anak usia dini merupakan salah satu bentuk penyelenggara pendidikan yang menitikberatkan pada pertumbuhan dan perkembangan fisik, kecerdasan, sosial emosional, bahasa, sesuai dengan keunikan dan tahap perkembangan yang dilalui oleh anak usia dini. Anak merupakan aset yang sangat berharga bagi setiap orang tua. Sebagai orang tua pasti menginginkan anak tumbuh dan berkembang dengan baik dan dapat memperoleh pendidikan yang dapat mengembangkan moral, akhlak dan budi pekerti yang baik (Harjaningrum, 2007: 2). Karakter adalah sebuah gaya, sifat, ciri, maupun karakteristik yang dimiliki seseorang yang berasal dari pembentukan atau tempaan yang didapatkan melalui lingkungan yang ada disekitarnya (Kusuma, 2007: 80). Terdapat beberapa nilai-nilai dalam pendidikan karakter yang harus dikembangkan, salah satunya adalah nilai karakter mandiri. Menurut Yuyun Nurfalah (2010: 12) mandiri dalam bahasa Jawa berarti berdiri sendiri atau tidak bergantungpada orang lain. Mandiri bisa juga diartikan sebagai suatu kemampuan seseorang untuk mewujudkan keinginan dan kebutuhan hidupnya dengan kekuatan sendiri. Selain itu menurut Yamin dan Sanan (2003: 83-84) anak dikatakan mandiri apabila ia mampu mengambil keputusan untuk bertindak, memiliki tanggung jawab dan tidak bergantung pada orang lain, melainkan percaya pada dirinya sendiri.

Pendidikan Anak Usia Dini yang saat ini menerapkan pembelajaran karakter sudah banyak bermunculan di Indonesia, salah satunya adalah TK Islam Al-Fajar Surabaya. TK Islam Al-Fajar Surabaya merupakan Pendidikan Anak Usia Dini yang berada di kota Surabaya, provinsi Jawa timur yang berlokasi di JL.Raya Medokan Sawah No.228, Kelurahan Medokan Ayu, Kecamatan Rungkut, Kota Surabaya. TK Islam Al-Fajar Surabaya merupakan Lembaga Pendidikan Anak Usia
Dini swasta yang ada di kota Surabaya yang sudah menerapkan model Pendidikan Holistik Berbasis Karakter (PHBK) yang berada di bawah naungan IHF (Indonesia Heritage Foundation). TK Islam Al-Fajar Surabaya adalah lembaga Pendidikan Anak Usia Dini berbasis Islam yang menerapkan nilai-nilai karakter pada anak usia dini melalui penanaman 9 pilar karakter salah satunya adalah karakter mandiri. Ditengah-tengah problematika yang terjadi seperti anak tidak mandiri, anak terlalu dimanjakan oleh orangtuanya, anak tidak mampu menghargai orang lain, anaktidak mampu mengendalikan dan menahan emosi. Apabila hal demikian dibiarkan secara terus menerus, maka anak akan mengalami sebuah hambatan dalam nenecahkan berbagai masalah dikemudian hari. Di khawatirkan pada di kehidupan dewasa nanti, anak menjadi pribadi yang tidak percayadiri (Komala, 2015), terlalu bergantung pada orang lain (Fauziah, Kusumawardani, \& Maryani, 2018; Komala, 2015), manja (Fauziah et al., 2018; Kumayang Sari, Kurniah, \& Suprapti, 2016), dan malas (Kumayang Sari et al., 2016). Oleh karena itu, TK Islam Al-Fajar Surabaya berupaya untuk menanamkan pembiasaan nilai karakter mandiri pada anak sejak usia dini. TK Islam Al-Fajar sudah membuat Standar Operasional Prosedur (SOP) yang kemudian diaplikasikan dalam kegiatan pembelajaran melalui kegiatan pembiasaan yang ada di sekolah untuk mengetahui standar tingkat pencapaian perkembangan anak.

TK Islam Al-Fajar Surabaya mempunyai beberapa kegiatan yang dapat melatih anak untuk memiliki karakter/ sikap mandiri sejak dini. Hasil observasi yang dilakukan oleh peneliti pada anak kelompok A pada tanggal 29 Agustus - 9 September 2019 di TK Islam AlFajar Surabaya peneliti melihat kelebihan dari TK Islam Al-Fajar Surabaya yang telah menerapkan penanaman nilai karakter mandiri pada anak sejak usia dini terlihat melalui kegiatan pembelajaran yang ada di sekolah antara lain : pada kegiatan awal masuk kelas pada kegiatan circle time (pembuka) anak diarahkan untuk duduk dengan rapi untuk berdo'a bersama-sama di aula. Kemudian setelah kegiatan circle time selesai anak dirahkan oleh guru untuk masuk ke dalam kelas dengan melepas sepatu, peci dan tas 
kemudian anak meletakkannya ditempat yang telah disediakan. Pada saat kegiatan inti penanaman kemandirian anak terlihat pada saat guru mengajak anak untuk bercerita tentang konsep pilar karakter mandiri agar anak menjadi lebih paham dan mengerti apa yang dimaksud dengan mandiri, kemudian guru mengajak anak berdiskusi dan bernyanyi (affirmation) sebagai penekanan penanaman nilai karakter mandiri pada anak, kemudian guru membiasakan anak untuk merapikan mainannya sendiri setelah bermain dan dipastikan anak memang melakukannya sendiri tanpa bantuan orang lain.

Pada kegiatan penutup guru selalu mengajak anak untuk berdiskusi/recallingagar penanaman nilai karakter mandiri lebih terpatri dalam diri anak, kemudian sebelum keluar kelas anak dibiasakan untuk mengenakan tas, peci dan sepatunya sendiri, kemudian anak berbaris dengan rapi tanpa bantuan guru. Bebrapa hal tersebut menjadi sebuah program unggulan yang dimiliki oleh TK Islam Al-Fajar Surabaya yang membedakan dengan lembaga yang lainnya dengan menerapkan metode pembiasaan yang dilakukan oleh guru kepada anak yang kemudian dilaporkan dalam raport khusus yang berisi laporan perkembangan pembentukan karakter anak agar mengetahui tingkat pencapaian perkembangan karakter anak, khusunya nilai karakter mandiri. Tidak terlepas dari itu TK Islam Al-Fajar Surabaya juga melakukan kerjasama dengan pihak orangtua agar penanaman nilai karakter mandiri yang sudah diterapkan di sekolah juga di terapkan oleh orang tua pada saat anak di rumah agar penanaman nilai karakter mandiri tersebut lebih terpatri pada diri anak, hal tersebutlah yang membuat peneliti semakin tertarik untuk mengkaji lebih dalam tentang penanaman nilai karakter mandiri pada anak kelompok A di TK Islam Al-Fajar Surabaya. Oleh karena itu peneliti memiliki keinginan untuk melakukan penelitian di TK Islam AlFajar Surabaya maka penelitian ini dibuat peneliti dengan judul "Penanaman Kemandirian Pada AnakUsiaDini (Studi kasus di Kelompok A Di TK Islam Al-Fajar Surabaya")

\section{METODE PENELITIAN}

Penelitian ini adalah penelitian jenis kualitatif yang menggunakan pendekatan deskriptif yang artinya penelitian ini mendeskripsikan sebuah kegiatan yang ada di salah satu lembaga pendidikan sesuai dengan fakta yang ada di lapangan tanpa sedikitpun merekayasa. Teknik pengumpulan datadalam penelitian kualitatif deskriptif ini yaitu menurut Sugiyono (2015: 309) teknik pengumpulan data dapat dilakukan melalui tiga cara yaitu dengan cara: observasi, wawancara, dan dokumentasi. Ketiga teknik pengumpulan data tersebut dapat digunakan, sehingga peneliti benar-benar mendapatkan data yang valid yang kemudian di analisa dan dilaporkan dalam bentuk kata-kata deskriptif sesuai dengan fakta yang ada di lapangan. Penelitian kualitatif deskriptif ini bertujuan untuk mendeskripsikan penanaman nilai karakter mandiri pada anak kelompok A di TK Islam Al-Fajar Surabaya. Adapun sumber data yang digunakan pada penelitian ini yaitu subjek berjumlah 27 partisipan yang terdiri dari 1 orang kepala sekolah, 6 orang guru kelompok A, 10anak kelompok A dan 10 orangtua (wali murid anak kelompok A TK Islam AlFajarSurabaya). Penentuan subjek dalam penelitian ini ditentukan menggunakan teknik snowball sampling. Teknik snowball sampling ini digunakan untuk mencari informasi dari informan satu ke informan lain sehingga data yang diperoleh banyak, lengkap, mendalam, dan data yang diperoleh benar-benar valid. Penggunaan tekniksnowball sampling ini akan berhenti jika data yang diperoleh peneliti benarbenar jenuh.Tempat penelitian ini hanya dilakukan oleh peneliti di TK Islam Al-Fajar Surabaya yang berlokasikan di JL.Raya Medokan Sawah No. 228, Kelurahan Medokan Ayu, Kecamatan Rungkut, Kota Surabaya.

Teknik analisis data dalam penelitian kualitatif deskriptif ini dilakukan pada saat pengumpulan data berlangsung sampai dengan selesainya pengumpulan data pada teknik tertentu. Teknik analisis data pada penelitian ini menggunakan teknik analisis Miles dan Huberman. Teknik Miles dan Huberman ini memiliki tiga langkah yaitu data reduction (reduksi data), data display (penyajian data), dan conclusion drawing/ verification (dalam Sugiyono, 2015: 337) berpendapat bahwa analisis data kualitatif ini dilakukan secara interaktif dan berlangsung secara terus-menerus sampai tuntas, sehingga data yang di peroleh peneliti sudah benar-benar jenuh dan valid. Proses analisis data Miles dan Huberman (dalam Afrizal, 2014: 180) tersebut dapat digambarkan sebagai berikut : 


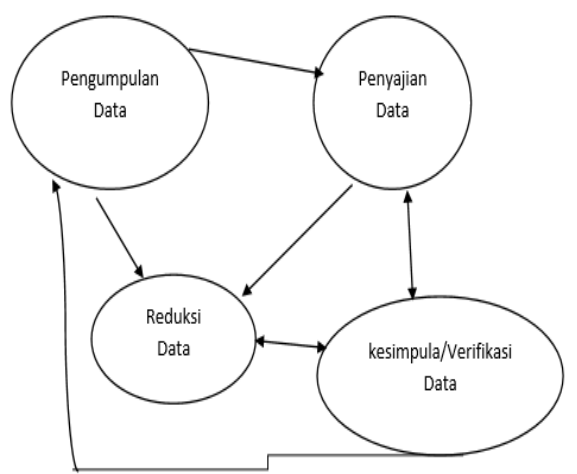

Gambar 1. Hubungan antara Analisis data dengan Pengumpulan Data Menurut Miles dan Huberman

Penelitian kualitatif deskriptif ini menggunakan teknik pengabsahan data uji kredibilitas yaitu mencakup perpanjangan pengamatan, meningkatkan ketekunan, triangulasi sumber data dari berbagai sumber yang kemudian dideskripsikan, dikategorikan mana pandangan yang sama dan yang berbeda dari sumber yang diperoleh dari informan tersebut. Data yang telah didapat kemudian dianalis oleh peneliti dan dimintakan member check ke berbagai sumber/ informan yang digunakan oleh peneliti untuk memperoleh data yang valid. Lalu peneliti menggunakan uji keabsahan data melalui : uji kredibilitas, uji transferbilitas, dan uji konfirmabilitas sehingga data yang peneliti peroleh benar-benar valid sesuai dengan fakta yang ada di lapangan.

\section{HASIL DAN PEMBAHASAN}

Penelitian kualitatif deskriptif ini adalah penelitian yang telah dilakukan oleh peneliti untuk melihat penanaman nilai karakter kemandirian pada anak kelompok A di TK Islam Al-Fajar Surabaya yang kemudian dilakukan pembahasan dengan cara mendeskripsikan data yang diperoleh peneliti selama penelitian berlangsung dengan cara melihat hasil observasi awal, hasil wawancara, dan catatan dokumentasi yang sudah terkumpul. Kemudian diolah, dianalisis dan dideskripsikan oleh peneliti sebagai berikut :

Hasil observasi berdasarkan pedoman instrumen yang terbagi menjadi dua pedoman yakni: 1. instrumen penanaman nilai karakter, mandiri dan 2. instrumen penilaian karakter mandiri. Kedua instrumen ini dapat memberikan sebuah gambaran bahwa penanaman nilai karakter mandiri pada anak kelompok A di TK Islam Al-Fajar
Surabaya mempunyai serangkaian proses perencanaan yang dimulai dari perencanaan kegiatan oleh kepala sekolah dan guru yang kemudian bekerja sama dengan orangtua dengan mengadakan kegiatan parenting bersama orangtua setiap satu bulan sekali.

Nilai-nilai karakter mandiri yang ditanamkan pada anak kelompok A TK Islam Al-Fajar Surabaya adalah nilai pilar karakter mandiri yang bersumber dari buku pilar karakter milik IHF (Indonesia Heritage Foundationn) yang bersumber dari buku yang ditulis oleh ibu Dr. Ratna Megawangi,M.Sc.

Kegiatan penanaman nilai karakter mandiri yang ada di TK Islam Al-Fajar Surabaya dapat dilihat terlebih pada proses pembelajaran. Kegiatan penanaman nilai karakter ini dimulai pada saat awal pembelajaran/ pembuka, inti, dan penutup baik saat kegiatan sentra maupun kegiatan ekstra. Hal tersebut terlihat pada kegiatan pembiasaan pada anak pada kegiatan awal masuk kelas pada kegiatan circle time (pembuka) anak diarahkan untuk duduk dengan rapi untuk berdo'a bersama-sama di aula. Kemudian setelah kegiatan circle time selesai anak diarahkan untuk masuk ke dalam kelas.

Sebelum masuk ke dalam kelas anak diarahkan oleh guru untuk berbaris sendiri dengan rapi di depan kelas, kemudian anak diarahkan oleh guru untuk melepas sepatu (Rizkyani, Adriany, \& Syaodih, 2020; Affrida, 2017); Pengasuhan et al., 2019), peci dan tasnya sendiri kemudian anak diarahkan untuk meletakkan sepatu(Pengasuhan et al., 2019), peci dan tasnya sendiripada tempat yang telah disediakan (Rizkyani et al., 2020; Affrida, 2017). Hal ini merupakan kegiatan yang dapat menstimulasi kemandirian anak yang sesuai dengan nilai pilar karakter kemandirian. Pada saat kegiatan inti, penanaman kemandirian anak distimulasi guru dengan mengajak anak untuk bercerita tentang konsep pilar karakter mandiri agar anak menjadi lebih paham dan mengerti apa yang dimaksud dengan mandiri, kemudian guru mengajak anak berdiskusi dan bernyanyi (affirmation) sebagai penekanan penanaman nilai karakter mandiri pada anak, kemudian guru meminta anak untuk merapikan mainannya sendiri (Komala, 2015) setelah bermain dan dipastikan anak memang melakukannya sendiri tanpa bantuan orang lain. 
Pada kegiatan penutup guru selalu mengajak anak untuk berdiskusi/recalling agar penanaman nilai karakter mandiri lebih terpatri dalam diri anak, kemudian sebelum keluar kelas anak dibiasakan untuk mengenakan tas, peci dan sepatunya sendiri, kemudian anak berbaris dengan rapi tanpa bantuan guru. Kesemua kegiatan tersebut menjadi program unggulan yang dimiliki oleh TK Islam Al-Fajar Surabaya.

Wawancara dilakukan oleh peneliti kepada kepala sekolah, guru kelompok A dan orangtua wali murid anak kelompok A. Hal ini didasarkan pada kedalaman informasi yang mereka miliki mengenai penanaman nilai karakter mandiri pada anak baik saat anak di sekolah atau saat anak di rumah. Catatan wawancara juga digunakan oleh peneliti sebagai salah satu data pendukung saat observasi sedang dilakukan sehingga peneliti dapat mendapatkan data yang transparan dan valid. Hasil wawancara yang dilakukan peneliti kepada 1 kepala sekolah, 6 guru kelompok A, 10 anak kelompok A dan 10 orangtua anak kelompok A TK Islam Al-Fajar Surabayadapat memberikan sebuah gambaran informasi pada peneliti antara lain sebagai berikut :

Penanaman nilai karakter mandiri pada anak kelompok A di sekolah TK Islam Al-Fajar Surabaya diajarkan pada saat anak awal masuk tahun ajaran baru, sehingga penanaman nilai karakter mandiri pada anak ini menjadi salah satu program unggulan yang dimiliki oleh TK Islam Al-Fajar Surabaya. Adapun bentuk nyata dari kegiatan penanaman nilai karakter mandiri yang ada di TK Islam Al-Fajar Surabaya dapat terlihat dari kegiatan pembiasaan pada anak ketika saat awal pembelajaran/ pembuka, inti, dan penutup baik saat kegiatan sentra maupun kegiatan ekstra.

Hal tersebut terlihat pada kegiatan pembiasaan pada anak pada kegiatan awal masuk kelas pada kegiatan circle time (pembuka) anak diarahkan untuk duduk dengan rapi untuk berdo'a bersama-sama di aula. Kemudian setelah kegiatan circle time selesai anak diarahkan oleh guru untuk masuk ke dalam kelas dengan melepas sepatu, peci dan tas kemudian anak meletakkannyaditempat yang telah disediakan.

Pada saat kegiatan inti penanaman kemandirian anak terlihat saat anak merapikan mainannya sendiri setelah bermain dan dipastikan anak memang melakukannya sendiri tanpa bantuan orang lain. Pada kegiatan penutup guru selalu mengajak anak untuk berdiskusi/ recalling agar penanaman nilai karakter mandiri lebih terpatri dalam diri anak, kemudian sebelum keluar kelas anak dibiasakan untuk mengenakan tas, peci dan sepatunya sendiri, kemudian anak berbaris dengan rapi tanpa bantuan guru.

Kepala sekolah, guru, dan staf administrasi selalu memberikan contoh pada anak saat anak di sekolah dan membiasakan anak untuk bersikap sesuai dengan nilai karakter mandiri, kemudian anak menirukan apa yang telah dicontohkan oleh guru sehingga anak menjadi terbiasa untuk menerapkannya sendiri dalam kehidupan sehari-hari tanpa harus meminta bantuan orang lain.

Dari wawancara yang ditujukan kepada 10 orangtua hasil menunjukkan bahwa orangtua selalu memberikan contoh sikap/karakter mandiri pada anak saat anak di rumah dan membiasakan anak untuk bersikap mandiri, kemudian anak menirukan apa yang telah di contohkan oleh orangtua sehingga anak menjadi terbiasa untuk melakukan segala sesuatu sendiri dalam kehidupan sehari-hari tanpa harus meminta bantuan dari orang lain. Adapun kegiatan tersebut yaitu: anak diajarkan untuk terbiasa melepas, memakai sepatu dan pakaian sendiri, anak dibiasakan untuk pergi ke toilet sendiri dan anak tidak ditemani oleh orangtua saat bersekolah.

Dari hasil pengamatanoleh peneliti terhadap 10 orang anak kelompok A di TK Islam Al-Fajar Surabaya, hasil menunjukkan bahwa dari ke 10 orang anak ini tidak semua anak bisa melakukan segala sesuatunya sendiri. Masih terdapat 3 orang anak yang memerlukan bimbingan dari orangtua dan guru.

Ada beberapa faktor-faktor yang dapat mendukung dan menghambat kegiatan penanaman nilai karakter mandiri pada anak kelompok A TK Islam Al-Fajar Surabaya. Faktor pendukungnya adalah peran kepala sekolah, guru, dalam menerapkan dan memberikan contoh nilai karakter mandiri di sekolah, sedangkan faktor penghambatnya adalah lingkungan anak di luar sekolah (orangtua, teman sebaya dan lingkungan masyarakat) yang tidak mendukung penerapan 
nilai karakter mandiri yang sudah diberikan pada anak saat di sekolah.

Harapan kepala sekolah, guru dan orangtua setelah diterapkan penanaman nilai karakter mandiri pada anak saat di sekolah atau di rumah yaitu nilai karakter mandiri yang sudah diterapkan pada anak diharapkan dapat menjadi sebuah kebiasaan hingga menjadi sebuah bekal yang dapat membawa anak untuk memiliki sikap atau karakter mandiri hingga anak dewasa kelak sehingga anak dapat melakukan segala aktivitasnya sendiri tanpa harus bergantung dan tanpa harus meminta bantuan orang lain.

Adapun metode khusus yang digunakan kepala sekolah, guru dan orangtua anak kelompok A TK Islam Al-Fajar Surabaya untuk menanamkan nilai karakter mandiri pada anak yaitu menggunakan metode pembiasaan, metode bercerita, metode affirmation, bernyanyi, syair, dan metode knowing, feelieng, dan action/praktik langsung baik di sekolah maupun di rumah agar penerapan nilai karakter mandiri lebih terpatri dalam diri anak seperti yang dikemukakan oleh Lickona (dalam Megawangi, 2007: 108).

Adapun catatan dokumentasi pada penelitian kualitatif deskriptif ini meliputi: dokumentasi foto kegiatan anak dan video kegiatan penanaman nilai karakter mandiri pada anak saat anak di sekolah dan di rumah, kemudian dokumentasi foto berupa buku pilar karakter mandiri, foto buku cerita yang berkaitan dengan karakter mandiri, foto raport pembentukan karakter, foto RPPH, dan foto visi-misi sekolah TK Islam Al-Fajar Surabaya.

Hasil dari penelitian kualitatif deskriptiff ini memberikan sebuah gambaran kegiatan penanaman nilai karakter mandiri pada anak sebagai sebuah stimulasi yang diberikan pada anak agar anak memiliki kebiassan untuk bersikap mandiri tanpa meminta bantuan dari orang lain.. Berdasarkan hasil penelitian dan hasil analisis semua data yang diperoleh, oleh peneliti maka penelitian ini dilakukan dengan tujuan mengetahui penanaman nilai karakter mandiri pada anak kelompok A di TK Islam AlFajar Surabaya.

Berdasarkan uraian di atas maka dapat tergambarkan bahwa penanaman nilai karakter mandiri pada anak kelompok A di TK Islam
Al-Fajar Surabaya adalah salah satu bentuk upaya yang dilakukan oleh TK Islam Al-Fajar Surabaya agar anak terbiasa untuk memiliki karakter atau sikap mandiri sejak usia dini.

\section{SIMPULAN DAN SARAN}

Berdasarkan hasil penelitian yang telah dilakukan maka dapat disimpulkan bahwaTK Islam Al-Fajar memberikan penanaman kemandirian pada anak melalui kegiatan awal hingga kegiatan akhir. TK Islam Al Fajar Surabaya juga menunjukkan bahwa dalam proses penanaman nilai karakter mandiri peran guru, kepala sekolah, dan juga staf administrasi sangat berperan penting, karena anak adalah peniru yang ulung maka peran guru, kepala sekolah, dan juga staf administrasi merupakan teladan atau model bagi murid-murid di sekolah dengan selalu memberikan contoh pada anak baik secara spontan ataupun secara pembiasaan, dan pengkondisian.

Selain itu, peran orangtua terhadap penanaman nilai karakter mandiri pada anak saat berada di rumah juga sangat berperan penting terhadap stimulasi penanaman nilai karakter mandiri yang diberikan pada anak saat di sekolah. Agar berjalan dengan optimal maka lingkungan sekolah dan lingkungan rumah harus selaras.

Adapun saran dari peneliti mengenai penanaman nilai karakter mandiri pada anak kelompok A di TK Islam Al-Fajar Surabaya adalah sebagai berikut: pertama, diharapkan lembaga/sekolah TK Islam Al-Fajar Surabaya dapat menambah pengetahuan pada orangtua dan anak terkait dengan penanaman nilai karakter mandiri pada anak melalui kegiatan yang telah diajarkan di sekolah. Hal ini akan menjadi salah satu potensi unggulan yang dimiliki lembaga pendidikan anak usia dini TK Islam Al-Fajar Surabaya yang membedakan dengan TK yang lain yang ada di Surabaya.

Kedua, penelitian ini dapat dijadikan sebagai masukan atau informasi bagi guru dan orangtua dalam melaksanakan penanaman nilai karakter mandiri pada anak baik saat di sekolah maupun di rumah. Dan, ketiga, kepada peneliti selanjutnya diharapkan dapat melakukan penelitian mengenai penanaman nilai karakter mandiri dengan lebih maksimal, sehingga dapat ditemukan hasil penelitian lain yang baru yang 
dapat menambah wawasan dunia pendidikan khususnya pendidikan anak usia dini.

\section{DAFTAR PUSTAKA}

Majid, A. (2011). Perencanaan pembelajaran mengembangkan kompetensi guru. Bandung: PT. Remaja Rosda Karya.

Affrida, E. N. (2017). Strategi ibu dengan peran ganda dalam membentuk kemandirian anak usia pra sekolah. Jurnal Obsesi: Jurnal Pendidikan Anak Usia Dini, 1(2), 114. Doi.org/10.31004/obsesi.v1i2.24.

A.R, Aisyah. (2014). The implementation of character education through contextual teaching and learning at personality development unit in The Sriwijaya University Palembang. International Journal of Education and Research. Vol. 2 No. 10.

Anas Salahudin. (2013). Pendidikan Karakter. Bandung: Pusaka Setia.

Arikunto. (2006). Metode penelitian kualitatif. Jakarta: Bumi Aksara.

Albertus, Doni Koesoema. (2010). Pendidikan karakter strategi mendidik anak di zaman global. Jakarta: PT.Grasindo.

Asmani, Jamal Ma'mur. (2012). Buku panduan internalisasi pendidikan karakter di sekolah. Yogyakarta: Diva press.

Koesoema, Doni. (2007). Pendidikan karakter: mendidik anak di zaman global. Jakarta: Grasindo.

Departemen Pendidikan Nasional. (2010). Pendidikan karakter teori \& aplikasi. Jakarta: Direktorat Jenderal Manajemen Pendidikan dan Menengah Kementerian Pendidikan Nasional.

Elkind, D.H. Sweet., Freddy. (2004). How to do character education.

Fauziah, R. R., Kusumawardani, R., \& Maryani, K. (2018). Perbedaan kemandirian anak ditinjau dari subyek pengasuhan orangtua dan kakek-nenek pada anak usia 5-6 tahun. Jurnal Penelitian Dan Pengembangan Pendidikan Anak Usia Dini, 5(1), 71.

https://doi.org/10.30870/jpppaud.v5i1.4684

Fakry, Gaffar. (2010). Pendidikan karakter berbasis Islam. Jogjakarta.

Gunawan, Heri. (2014). Pendidikan karakter konsep dan implikasi. Bandung: Alfabeta.

Harjaningrum, Agnes Tri. (2007). Peranan orang tua dan praktisi dalam membantu tumbuh kembang anak berbakat melalui pemahaman teori dan tren pendidikan. Jakarta: Prenada Media Group.

Josephson, M. (2013). Josephson institute of ethics and character Counts. www.JosephsonInstitute.org (diakses tanggal 2 Desember 2019).

Kesuma, Dharma. (2011). Pendidikan karakter kajian teori dan praktik di sekolah. Bandung: PT Remaja Rosdakarya.

Komala. (2015). Mengenal dan mengembangkan kemandirian anak usia dini melalui pola asuh orang tua dan guru. Tunas Siliwangi, 1(1), 31-45.

Kumayang Sari, A., Kurniah, N., \& Suprapti, A. (2016). Upaya guru untuk mengembangkan kemandirian anak usia dini di gugus hiporbia. Jurnal Ilmiah Potensia, 1(1), 1-6.

Lickona, Cronbach. (1992). Educating for character, how our schools can teach respect and responsibility. New York: Bantam Books.

Ayu, Lestari \& Simatupang, ND. (2018). Studi deskriptif penanganan guru menumbuhkan kemandirian dalam aktivitas belajar anak usia 4-5 tahun di TK Kartini Bojonegoro. Jurnal PAUD Teratai. Volume 7 Nomor 3.

Marzuki. (2015). Pendidikan karakter Islam. Jakarta: Amzah.

Mansur. (2005). Pendidikan anak usia dini dalam Islam. Yogyakarta: Pustaka Pelajar.

Moleong, J. Lexy. (2006). Metodologi penelitian kualitatif. Bandung: PT. Remaja Rosdakarya.

Megawangi, Ratna. (2007). Semua berakar pada karakter. Jakarta: Lembaga Penerbit FE-UI.

Megawangi, Ratna. (2010). Modul 9 pilar karakter. Depok: Indonesia Heritage Foundation.

Megawangi, Ratna. (2010). Pendidikan karakter solusi yang tepat untuk membangun bangsa. Jakarta: IHF (Indonesia Heritage Foundation).

Mulyasa, E. (2011). Manajemen pendidikan karakter. Jakarta: Bumi Aksara.

Mustafa, Bacharudin. (2008). Dari literasi dini ke literasi teknologi. Jakarta: Yayasan CREST

Puskur. (2010). Pengembangan pendidikan budaya dan karakter. dalam bahan pelatihan penguatan metodologi pembelajaran berdasarkan nilai-nilai budaya untuk membentuk daya saing dan karakter bangsa. Jakarta. 
Rizkyani, F., Adriany, V., \& Syaodih, E. (2020). Kemandirian anak usia dini menurut pandangan guru dan orang tua. Edukid, 16(2), 121-129. doi.org/10.17509/edukid.v16i2.19805

Sanan., Yamin. (2013). Panduan pendidikan anak usia dini. Jakarta: GP. Press.

Sujiono, Y.N. (2009). Konsep dasar pendidikan anak usia dini. Jakarta: PT Indeks.

Irzalinda, V., Sofia, A., G. F. A. (2019). Hubungan kualitas lingkungan keluarga dengan karakter anak usia dini. Paud Lectura: Jurnal Pendidikan Anak Usia Dini, Vol 3, No 1.

DOI: https://doi.org/10.31849/paudlectura.v3i01.3352

Zamroni. (2011). Paradigma pendidikan Indonesia. Yogyakarta: Griya Publishing. 